\title{
Multi-Criteria Approach Using Simulation-Based Balanced Scorecard for Supporting Decisions in Health-Care Facilities: an Emergency Department Case Study
}

Waleed Abo-Hamad

Technological University Dublin

Amr Arisha

Technological University Dublin, amr.arisha@tudublin.ie

Follow this and additional works at: https://arrow.tudublin.ie/buschmanart

Part of the Business Administration, Management, and Operations Commons

\section{Recommended Citation}

Abo-Hamad, W., \& Arisha, A. (2014). Multi-criteria approach using simulation-based balanced scorecard for supporting decisions in health-care facilities: an emergency department case study. Health Systems Journal, 3(1), 43-59. doi:10.1057/hs.2013.11

This Article is brought to you for free and open access by the School of Management at ARROW@TU Dublin. It has been accepted for inclusion in Articles by an authorized administrator of ARROW@TU Dublin. For more information, please contact arrow.admin@tudublin.ie, aisling.coyne@tudublin.ie,gerard.connolly@tudublin.ie.

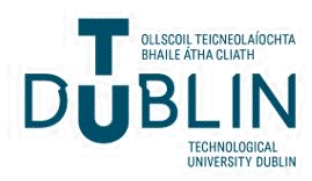




\title{
MULTI CRITERIA APPROACH USING SIMULATION-BASED BALANCED SCORECARD FOR SUPPORTING DECISIONS IN HEALTHCARE FACILITIES: AN EMERGENCY DEPARTMENT CASE STUDY
}

\begin{abstract}
Health research is a priority in every economy, and this research - set the context of building a more sustainable and efficient healthcare system - examines how operations management practices can be translated to clinical applications. Healthcare systems in general (and Emergency Departments in particular) around the world are facing enormous challenges in meeting the increasingly conflicting objectives of providing wide accessibility and delivering high quality services efficiency and promptly. The framework proposed in this study integrates simulation modelling, balanced scorecards, and multi-criteria decision analysis with the aim of providing a decision support system for healthcare managers. Using Analytic Hierarchy Process (AHP), simulation results are aggregated to achieve defined strategic as well as tactical and operational objectives. Communicating the significance of investigated strategies can encourage managers to implement the framework's recommendations in the Emergency Department within the partner hospital.
\end{abstract}

Keywords: Healthcare Management, Multi-Criteria Decision Making, Discrete-Event Simulation, Emergency Department, Complex Business Process

\section{INTRODUCTION}

Healthcare managers are currently under constant pressure to control rapidly escalating expenses, while still responding to growing demands for both high class patient service levels and medical treatment. Resolving such challenges requires a consistent understanding of healthcare systems which can be an overwhelming task, given the large number and diversity of the organisations involved and their high levels of uncertainty and interdependencies. Moreover, healthcare managers also face the challenge of intrinsic uncertainty of the demands and outcomes involved in healthcare systems; high levels of human involvement at both patient level and staff level; limited budget and resources; and a large number of variables (e.g., staff scheduling, bed availability, etc.). As well as seeking high service quality 
levels, patients are, understandably, less and less prepared to wait in queues for essential health services, so the healthcare service concept has shifted from optimising resource utilisation to finding the best balance between service for patients and efficiency for providers (Brailsford and Vissers, 2011). Dealing with the inevitable complexities in healthcare processes and services, and addressing the challenges involved in making informed decisions, are the foci of this research. The objective of this paper is to develop a simulation-based decision support framework to improve planning and efficiency of healthcare processes. A real-world case study of an emergency department in one of Dublin's largest university hospitals is investigated to help the hospital executive managers enhance patients' experience using the proposed framework.

\section{PROJECT BACKGROUND}

Overcrowding in Emergency Departments (EDs) has become a significant international crisis that negatively affects patient safety, quality of care, and patient satisfaction (Graff, 1999). Overcrowding in Irish EDs has been declared as a "National Emergency" in Ireland since 2006. Several national reports have highlighted a growing demand for emergency care $(1.2$ million patients attending EDs annually) and a simultaneous decrease in the number of operating EDs. The result has increased crowding, high percentages of patients leaving EDs before completing their treatment episodes and higher morbidity and mortality rates. Additionally, prolonged waiting times have been reported with more than 500 patients on trolleys for hospital admission every day; $18 \%$ of patients are waiting more than 24 hours and 40\% between 10-24 hours (HSE Performance Monitoring Report, 2010). Although Ireland is not alone in experiencing these figures (Schafermeyer and Asplin, 2003, Rowe et al., 2006, Forero et al., 2010), it is important not to underestimate the sometimes catastrophic consequences this situation has on patients, staff and the healthcare sector.

This project was a joint effort involving hospital staff (managers, consultants, doctors, nurses, and administrators) and Institute research team. The university hospital is an acute public hospital in North Dublin. This 570-bed hospital provides a variety of healthcare services, with a $24 \mathrm{hr}$ 'on-call' ED that receives over 55,000 patients annually. According to the task force report in 2007, the ED's overall physical space and infrastructure inadequate, and the hospital - which was operating at approximately $99 \%$ occupancy - had difficulty in accommodating surges in ED admission numbers. Therefore, patients who require critical care (ICU/HDC) beds suffer from significant delays and the ED could not meet the national 
target of 6-hrs average length of stay (LOS) for patients. The ED figures show a clear evidence of this overcrowding, with an average of $17 \%$ of its patients choosing to leave before being seen by ED clinician. The report also indicated that the average time from ED registration to discharge was $9.16 \mathrm{hrs}$, i.e. $3.16 \mathrm{hrs}$ over the $0-6 \mathrm{hr}$ metric set by the Health Service Executive (HSE), and the average time from registration to acute admission is 21.3 hrs with a standard deviation of 17.2 hrs (i.e., 3.5 times above the same national metric). Obviously, patients who are admitted will usually experience longer LOS times than those who are discharged due to delays between admission referral by an ED doctor, the allocation of a bed, and time taken to transfer the patient to that bed.

To cope with these challenges, a joint collaborative work was established with the hospital management team to develop a decision support Framework. This collaboration aims to identify performance bottlenecks and explore improvement strategies to meet the HSE targets.

\section{PROPOSED METHODOLOGY}

\section{Literature Review}

Over the past two decades, several performance measurement systems were introduced with the objective of achieving the full potential of performance measurement approaches (Fitzgerald et al., 1991, Kaplan and Norton, 1992, Lynch and Cross, 1995, Neely et al., 2002). Assessing performance is essential because it provides the capability to identify performance bottlenecks and taking corrective action before these problems escalate (Kueng, 2000).

The Balanced Scorecard (BSC) is one of the main performance measurement frameworks that use strategy-linked leading performance measures and actions for planning and implementing an organisation's strategy (Kaplan and Norton, 1996). The BSC was discussed as an appropriate tool for healthcare organisations as early as 1994 where Griffith (1994) places the BSC in the broader notion of championship management. Several articles have described financial success stories by using BSC in healthcare organisations, whether by solving financial crises (Jones and Filip, 2000, Meliones, 2000, Mathias, 2001) or by reducing costs (Berger, 2004, Colman, 2006). The BSC has also become a regular step in quality improvement within several healthcare organisations (Moullin, 2004). It has become a 
tool for developing quality plans and for evaluating quality improvement processes (Peters and Ryan, 1999, Colaneri, 1999).

While BSC has been applied successfully as a strategic management tool, there are many challenges in the design and implementation. The choice of performance perspectives and measures to be included in the BSC is one of the main challenges in designing BSCs in healthcare settings. Furthermore, the number of performance measures is challenged by the amount of resources tied up in the measurement process, in terms of data collection and analysis and the representation and interpretation of the measures (Gao et al., 2006). Finally, the interactions between the performance indicators within the BSC are, in most articles, assumed and treated as unproblematic issues (Aidemark and Funck, 2009), ignoring the fact that several indicators can oppose each other (Patel et al., 2008). Due to the large number of variables and high levels of uncertainties, BSC has to integrate with other analytical tools.

Several studies have combined Multi-Criteria Decision Analysis (MCDA) techniques with the BSC in order to overcome these challenges. Analytic Hierarchy Process (AHP) (Saaty, 1990) is applied by many authors for the selection of performance measures to be used in the BSC (Clinton et al., 2002, Searcy et al., 2004, Karra and Papadopoulos, 2005, Wu et al., 2009). Other multi-criteria analysis methods have also been applied in the design and evaluation of BSCs. For example, the Simple Multi-Attribute Rating Technique (SMART) can be used to select appropriate measures for the development of a BSC system in a financial institution (Valiris et al., 2005).

Despite the recognised importance of explicitly dealing with priorities and trade-off between different performance indicators (Banks and Wheelwright, 1985; Eccles and Pyburn, 1992; da Silveira and Slack, 2001), limited literature has addressed the nature of the tradeoffs between these measures and their inter-dependencies (Mapes et al., 1997, Neely et al., 2000). Understanding the causes of unsatisfactory performance levels and determining proper corrective actions requires, in most cases, understanding and detailed analysis of the underlined process and the consideration of trade-offs. However, the lack of analytical tools prevents decision makers to effectively process all the information necessary in order to develop and implement better-informed decisions and plans. Consequently, modelling and simulation is required (Sterman, 1989; Senge, 1990). 
Efforts to develop simulation models have advanced since the late 1980s where simulation was used to investigate the impact of key resources on waiting times and patient throughputs (Saunders et al., 1989), and it has since been used to study the effect of a wide range of health interventions on healthcare processes' performance (Dittus et al., 1996, Kim et al., 1999, Ingolfsson et al., 2003, Litvak et al., 2008. Simulation models can effectively be used as a predictive tool to predict the maximum demand level that an ED staff can handle, and consequently determine the required staffing level to meet that increase in demand and at the same time to keep the average waiting time of patients under a certain threshold (Baesler et al., 2003). A balance in the utilisation of resources would be attained by analysing the arrival pattern of patients, which can significantly improve staffing planning and resource allocation (Sinreich and Marmor, 2005. The bed occupancy level has been found to be strongly correlated with average length of stay of patients within the ED (Forster et al., 2003). By using simulation models, Elbeyli and Krishnan (2000) found that adding beds to other specialised units within the hospital decreased the average time of patients waiting to be admitted from the ED.

Most of the prior simulation studies have used a single perspective performance measure. Given the current complexity of the healthcare systems, multiple perspectives of performance is instrumental in operational and strategic decisions. BSC, MCDA, and simulation modelling are approaches that have independently proven their potential to inform and support the decision making process. There is also a clear potential for these approaches to be integrated and applied in a collaborative manner which can bring new insights to inform and support the different stages of the decision making process.

\section{Proposed Framework}

The main objective of this framework is to address the limitations in the literature and to provide healthcare managers and planners with an integrated decision support tool that can be used in an effective and practical manner. This section discusses the aspects and requirements for developing such a framework. Figure 1 gives an overview of the framework, and the following sub-sections provide detailed descriptions of each component, and highlight the coordination between them and their points of integration. 


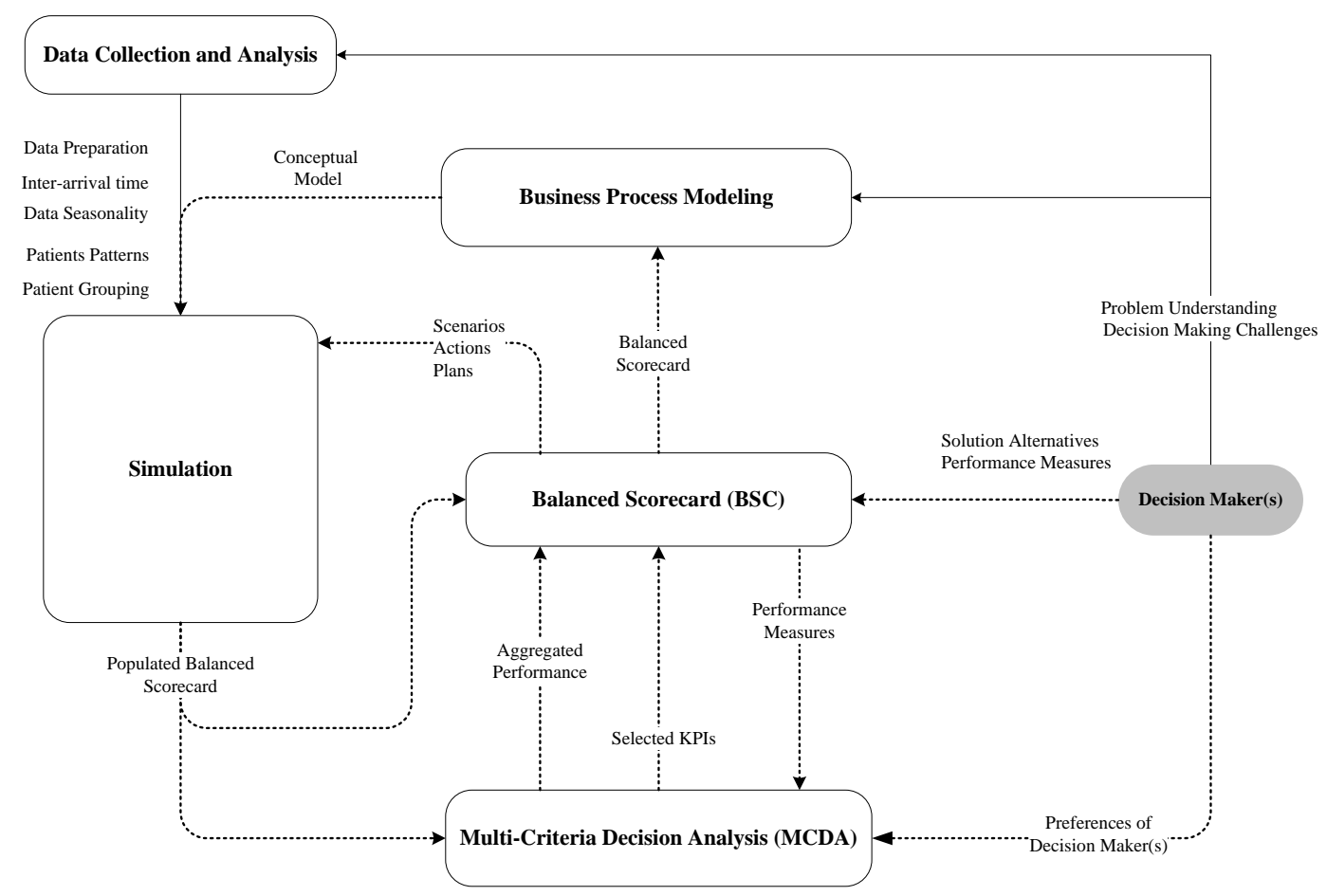

Figure 1 An overview of the integrated framework

\section{Business Process Modelling}

Defining the problem to be solved is one of the key elements in developing the framework. Healthcare systems contain high levels of social interactions that are characterised by complexity, particularly at decision points, with the result that healthcare service delivery and patient flow management problems are usually hard to define. Gaining a better understanding of the healthcare process is essential for making correct and justifiable decisions and providing effective solutions, so modelling the underlined business process requires that problems be understood from the point of view of the individuals directly involved in service delivery. The data collection phase combined interviews, focus groups, and quality circles with experts and practitioners, and this multiple method provided holistic insights about various system issues and aspects. The underlined business processes were then mapped into a conceptual process model using one of the well-developed modelling languages where subprocesses and activities are identified. The control flow definition is created by identifying the entities that flow through the system (e.g., patients, staff) and describing the connections that link different parts of the process, and resources are identified and assigned to activities where necessary. The process model must be verified to ensure it is logically valid and does not contain errors. 


\section{Simulation Modelling}

The process model was combined with the analysed empirical data into a dynamic simulation model, so that both the data collection phase and the business process modelling take place within the context of developing the simulation model. The procedure is often referred as model translation, because it involves transforming an abstract conceptual model into a more detailed and complex executable simulation model. To ensure that the credibility of the simulation model can be guaranteed, it must be both verified and validated. Verification ensures that the transformation of the conceptual model has been applied correctly so that the model's logic reflects the underlying business process, while validation involves comparing the outcome data of the simulation model with the data obtained during the data collection phase (Balci, 1997). Once the simulation model is verified and validated, the decision makers can use the replicated model to investigate a number of decisions and alternatives (i.e., whatif scenarios) to foresee their consequences.

\section{Integrating Balanced Scorecard and Simulation}

Although it can be applied in the context of healthcare management, the full potential of the BSC cannot be realised in this context because of its limitations and the challenges involved in its implementation. In order to alleviate the BSC's limitations in terms of its measurement capabilities and of its inability to identify cause-and-effect inferences between performance measures, an integration between BSC and simulation is proposed. Performance perspectives and performance measures are collected by interviewing senior managers of healthcare facilities (e.g. an emergency department). This step is essential to align the facility's performance measures with the strategic objectives of the national health authorities (i.e. HSE), so the simulation model will provide quantitative values of the performance measures, and qualitative measures (such as patient satisfaction) can be related to measurable indicators (such as average waiting and LOS times). Such integration allows for the evaluation of a wide range of actions and plans based on the recommendations of national reports and surveys, which can then be evaluated in the form of what-if scenarios, and the results used to populate the designed BSC.

The results are then evaluated and interpreted by decision makers, who provide guidance on the implementation of suggested decision alternatives and plans, as well as setting benchmarks of the maximum performance that can be achieved using the available resources and staffing levels. Thus integrating simulation and BSC helps focus efforts on strategic 
visions to obtain desired outcomes, assists in making better decisions, improves communication within the organisation, provides continual feedback on strategies, promotes adjustments to changes and assists both individuals and organisations in achieving their goals and objectives - at the same time the simulation process can provide interesting information about the cause-and-effect relationships among performance measures.

\section{Multi-Criteria Decision Analysis}

Though the BSC's measurement limitations can be resolved by integration it with simulation, the large number of measures in the BSC delays the evaluation and analysis of the results, especially where they may be conflicting or even opposed to each other. Multi-criteria decision analysis (MCDA) tools can play an important role in addressing these challenges and overcoming the problems of selecting and evaluating the key performance measures during the design phase of the BSC. In the design phase of the BSC, MCDA methods can be applied for the selection of appropriate performance measures, where decision-makers can evaluate and prioritise performance measures, which can then be illustrated in a value tree that represents the selected key performance indicators (KPIs). Following their selection, the resulting value tree is passed to the simulation model. MCDA can then effectively aggregate the simulation output (i.e., KPIs) into a marginal performance according to decision makers' preferences. This dual use of MCDA within the integrated framework can contribute greatly to making informed decisions for improving and managing healthcare business process.

\section{FRAMEWORK IMPLEMENTATION}

\section{An Emergency Department - A Case study}

The EDof the hospital has 13 monitored trolley spaces 3 of which are in a resuscitation area and are reserved for major trauma and critical care patients; an ambulatory care area (capacity six trolley spaces); two isolation rooms, a psychiatric assessment room, two rapid assessment triage bays as well as two other triage rooms. The layout of the ED is shown in Figure 2. Five distinct areas can be identified: a waiting room for walk-in patients waiting for triage, a diagnostics area (X-Ray and CT scan), an ambulatory care unit area (ACU), an ED resuscitation area (CPR) and an ED major assessment area. Patients arriving by ambulance usually in a critical condition - are routed directly to the resuscitation area, while patients whose conditions require monitoring stay in the major assessment area. The ambulatory care 
area is for patients arriving on foot, who may be suffering from abdominal pain, headache, limb problems, wounds, head injuries, facial problems, etc.

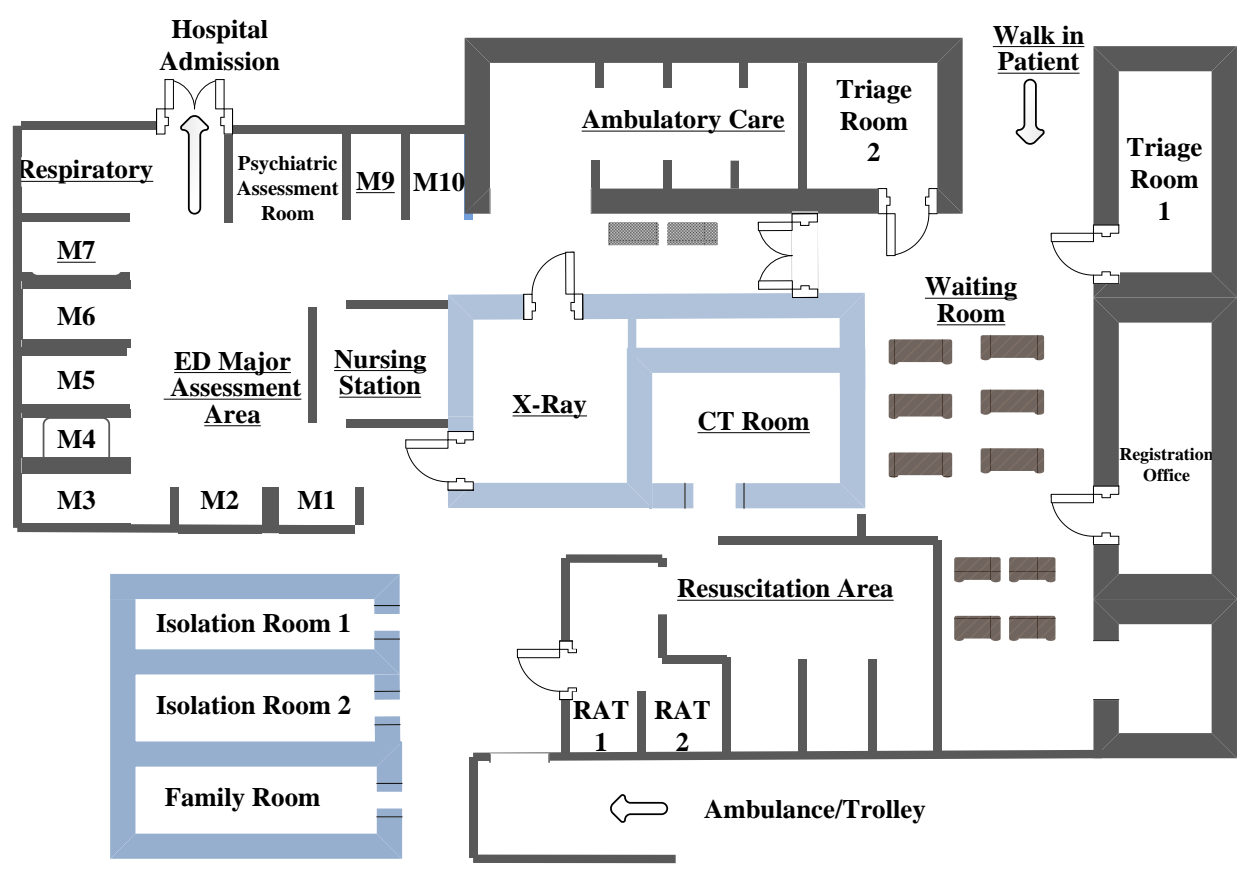

Figure 2 ED physical layout and main care areas

As a 24-hour department, the ED has three consultants, two nursing managers, and eleven nurses during the day and nine nurses at night, divided into six types of nurse; Advanced Nurse Practitioners (ANPs), triage nurses, resuscitation nurses, respiratory nurses, majors/minors nurses, and healthcare assistants. Physicians (excluding the three Consultants who provide cover between 9am-5pm (or $8 \mathrm{am}-8 \mathrm{pm}$ ) with $24 / 7$ on-call provision) are divided into three types: registrar/specialist registrars; Senior House Officers (SHOs), and interns, and are distributed as follows when the roster allows: three registrars per day working $10 \mathrm{hr}$ shifts starting at $8 \mathrm{am}, 12 \mathrm{pm}$, and $10 \mathrm{pm}$; two interns working daily $8 \mathrm{am}$ to $5 \mathrm{pm}$ shifts Monday to Friday; and twelve SHOs working fixed shifts during the day and night to keep the ED running. So the numbers of doctors on duty varies between 2 and 7 depending on the time of day or night).

\section{Process Mapping}

A variety of data collection methods such as interviews, focus groups, observations, and historical data were used to develop a comprehensive conceptual model for the ED. Four preliminary interview sessions with senior managers (two ED consultants and two nursing 
managers) were carried out in order to gain insights about the current challenges they face in managing their department. A better understanding for healthcare processes, activities, challenges, and variables was acquired with valuable insights of the challenges in the decision making process. The interviews helped to develop significant inputs that critically supported the development and validation phases of the proposed framework. This was

followed by constructing a focus group of ED doctors (one registrar and three SHOs) and nurses (a triage nurse, one ANP, and two general nurses) where a weekly meeting was scheduled for discussing issues such as general patient care paths, categories of patients and their complexities, and resources availability and capacity issues. Meanwhile, a number of visits have been made to the ED (i.e. site visits) with the objective of analysing the ED layout which reflects how resources are allocated and utilised within the ED. A high level understanding of the journey of patient through the ED was acquired from the initial findings of the interviews. Upon the arrival of walk-in patients (self- or-GP referred), they register and wait in the waiting area to be triaged. - When their name is called (depending on triage staff availability) they are generally assessed by a triage nurse. Based on their condition and triage assessment, each patient is assigned a clinical priority (triage category) according to the Manchester Triage System (MTS) that is widely used in UK, Europe, and Australia (Cronin, 2003), which uses a five level scale for classifying patients according to their care requirements; immediate, very urgent, urgent, standard, and non-urgent. Once a triage category is assigned, the patient may be sent back to the waiting room until a bed or trolley is available in area where they can be given treatment appropriate to the type and intensity of their care needs. Waiting times for patients will depend on their triage category of patient and the availability of both medical staff (i.e. ED physician or ANP) and empty trolleys, which are a prerequisite for full and accurate assessment. After they have been assessed by an ED clinician, a decision is made either to discharge or to admit. These are the primary care stages which apply to all patients, whether they are discharged from or admitted to hospital. Secondary patient stages are those steps which may be involved in the care of some (but not all) patients such as diagnostics (e.g. X-Rays, blood tests, etc), and further ED-doctor assessment or consultation with a medical/surgical specialty doctor to confirm whether a patient should be admitted or to gain advice on the best possible treatment for a patient being discharged. Figure 3 shows a detailed flowchart for patient journey through the ED. 


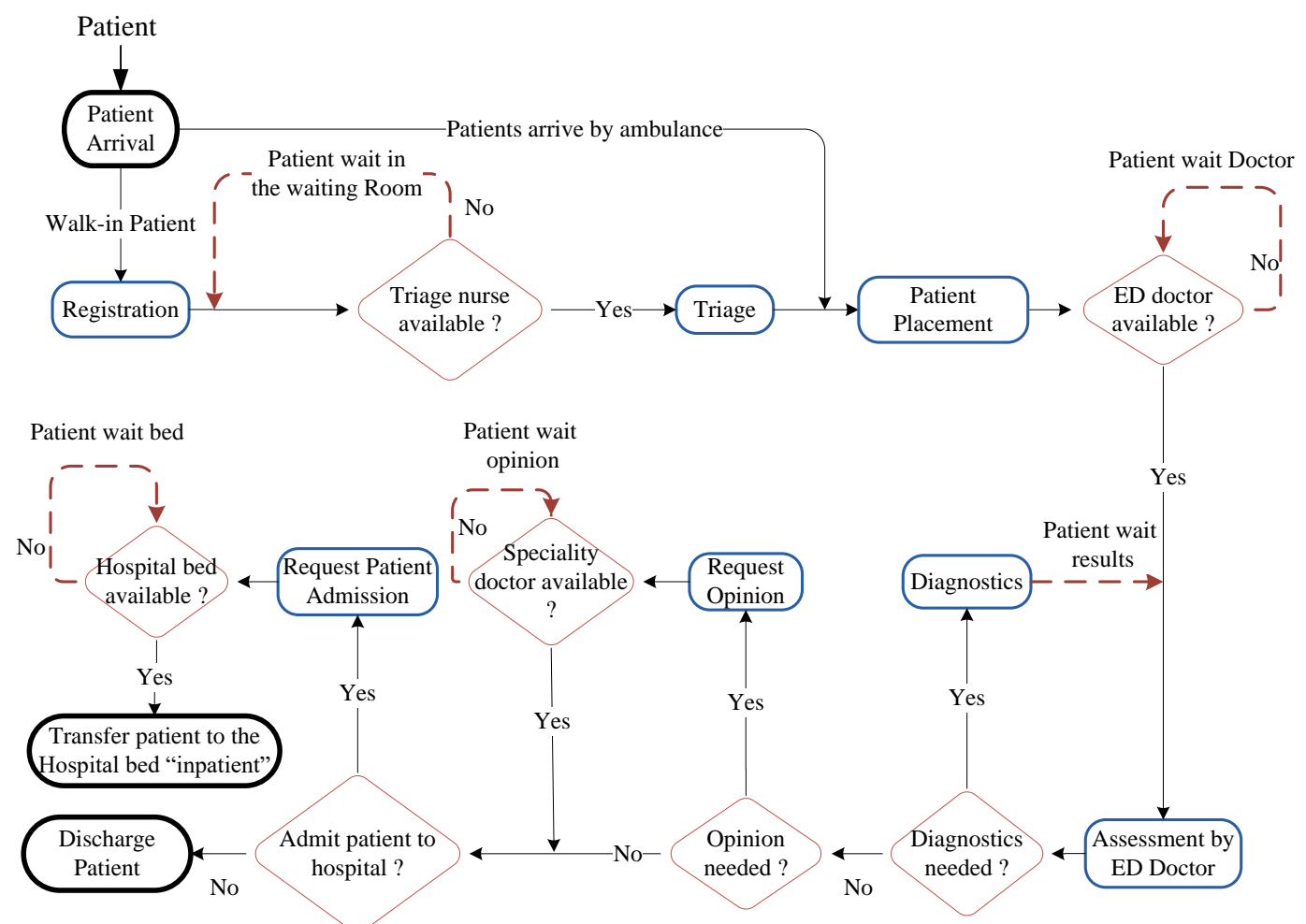

Figure 3 Detailed patient flow through the ED

The developed flow charts for patient flow were effective in fast and informal representation of process representation, and therefore they are effective in communication and discussions between analysts and stakeholders. However, flow charts use a sequential flow of actions, do not support a breakdown of activities (Aguilar-Saven, 2004), and they lack the necessary semantics to support more complex and standardized constructs (Havey, 2005). Therefore, furthermore different levels of details about the patient flow were collected by site visits by the research team. Site visits were carried out two times per week where different weekdays were selected at different hours (i.e., morning, afternoon, and night time). This was an essential step in order to observe the variability of care service demand (i.e., patient arrival) and to note the processes that the patient goes through. Based on the analysis of this stage, each ED process was broken down into smaller sub-functions, and key resources (e.g. staff and medical equipments) at each care stage are identified and detailed using IDEF0. IDEF0 is a structural graphical representation of processes or complex systems that allows the analysis and communication of the functional aspect of a system (NIST, 1993). Each process in IDEF0 is described as a combination of activities, inputs, controls and mechanisms in a hierarchical fashion. At the highest level the representation may be of an entire process. The processes can be further decomposed to show lower-level activities. The 
breakdown of processes may continue until a point where sufficient detail is reached (Colquhoun et al., 1993). This hierarchical structure of IDEF0 keeps the model scope within the boundaries and allows the system to be easily refined into more detail until the model is as descriptive as necessary for the decision maker (Kim and Jang, 2002). The top level of the developed IDEF0 model for the ED is shown in Figure 4. The main unit of an IDEF0 model is an activity block that describes the process's main function, with ICOMs (Input, Control, Output and Mechanism) represented by horizontal and vertical arrows. Process control (top arrow) can be patient information (e.g. arrival time, triage category and presenting complaint), safety regulations, or national/international standards whereas process mechanisms are usually the agents and/or physical resources which facilitate the activity (e.g. ED physicians, nurses, and beds/trolleys).

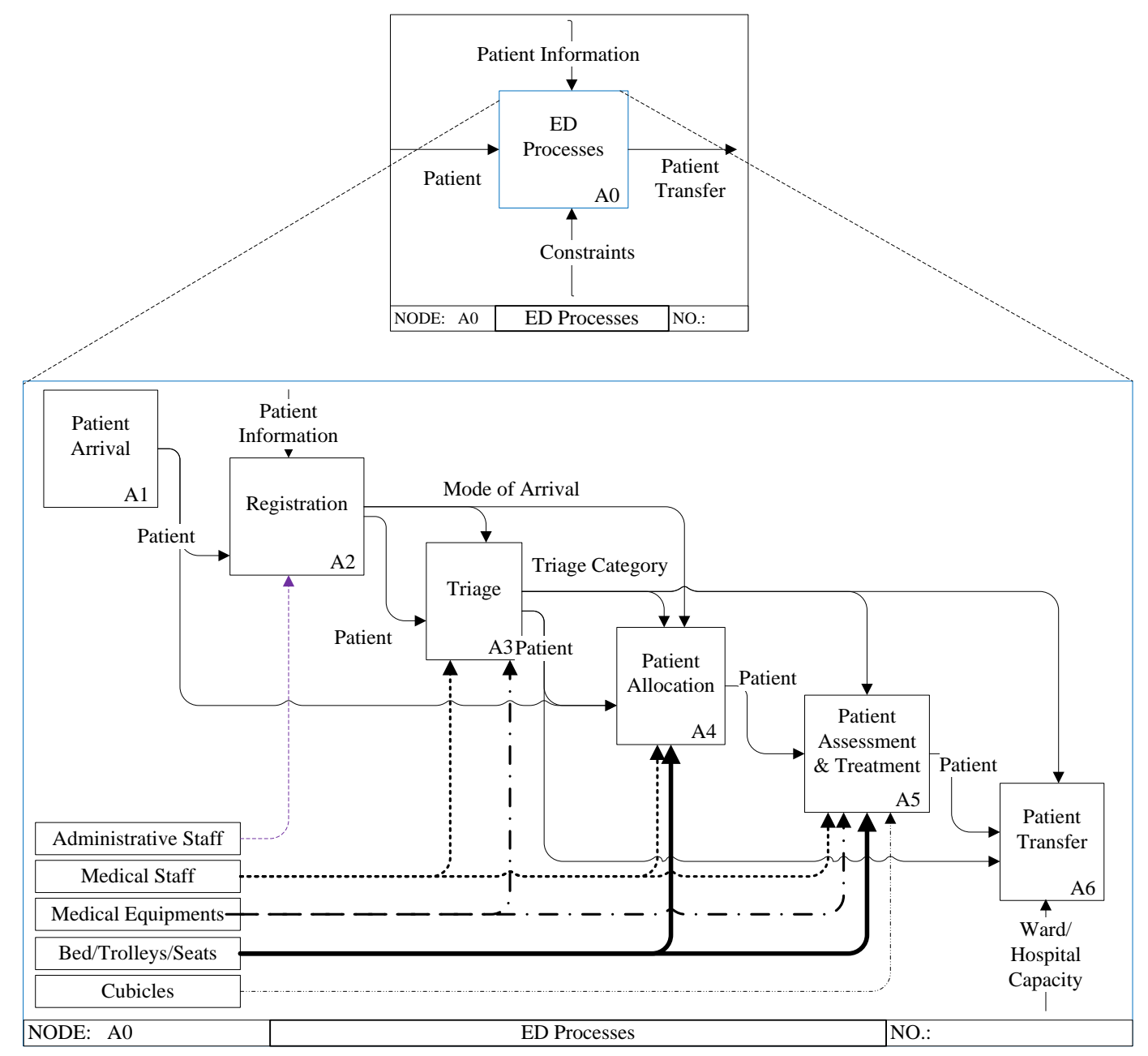

Figure 4 Mapping main ED processes 


\section{A Balanced Scorecard for the Emergency Department}

In conjunction with the process mapping phase, a number of interviews with ED senior managers (two consultants, and two nurse managers) has taken place to collect information about the performance areas and performance measures. Incorporating these measures at that stage was very useful for developing the balanced scorecard for the ED and setting the objectives of the simulation model. The findings of this stage resulted in the selection of four performance perspectives in the design of BSC: community, patient, internal business processes, and learning and growth. An overview of these perspectives is given in Figure 5 and a brief detail for performance measures in each perspective is discussed.

Community Engagement Perspective: This perspective brings HSE performance targets and national Emergency Medicine Program (EMP) measures into the BSC. The HSE performance target is that all patients be processed through the ED within 6 hours of arriving, before 'separation' (i.e., including discharge or admission where relevant), while the overarching aims of the EMP are to improve the safety and quality of patient care in EDs and to reduce waiting times for patients. In designing the ED BSC, 'patient' was selected as a sole perspective and 'patient satisfaction' as its main measure. The efficiency of internal ED processes impacts patient satisfaction levels, so average patient waiting and LOS times are connected to this performance measure. The main objective in Internal Business Processes perspective is to improve the ED performance in terms of its layout efficiency, ED productivity, resource utilisation and patient throughput. The layout efficiency measures the average daily distances travelled by doctors and nurses, while the ED productivity is measured in terms of five indicators: the ratio of patients per doctor, the ratio of patients per nurse, the percentage of patients treated, the percentage of patients admitted to the hospital, and the percentage of patients who leave the ED without treatment. Resource utilisation is measured for two types of resources: ED staff and ED assets such as major trolleys, ambulatory care units (ACUs), and resuscitation rooms (CPRs). 


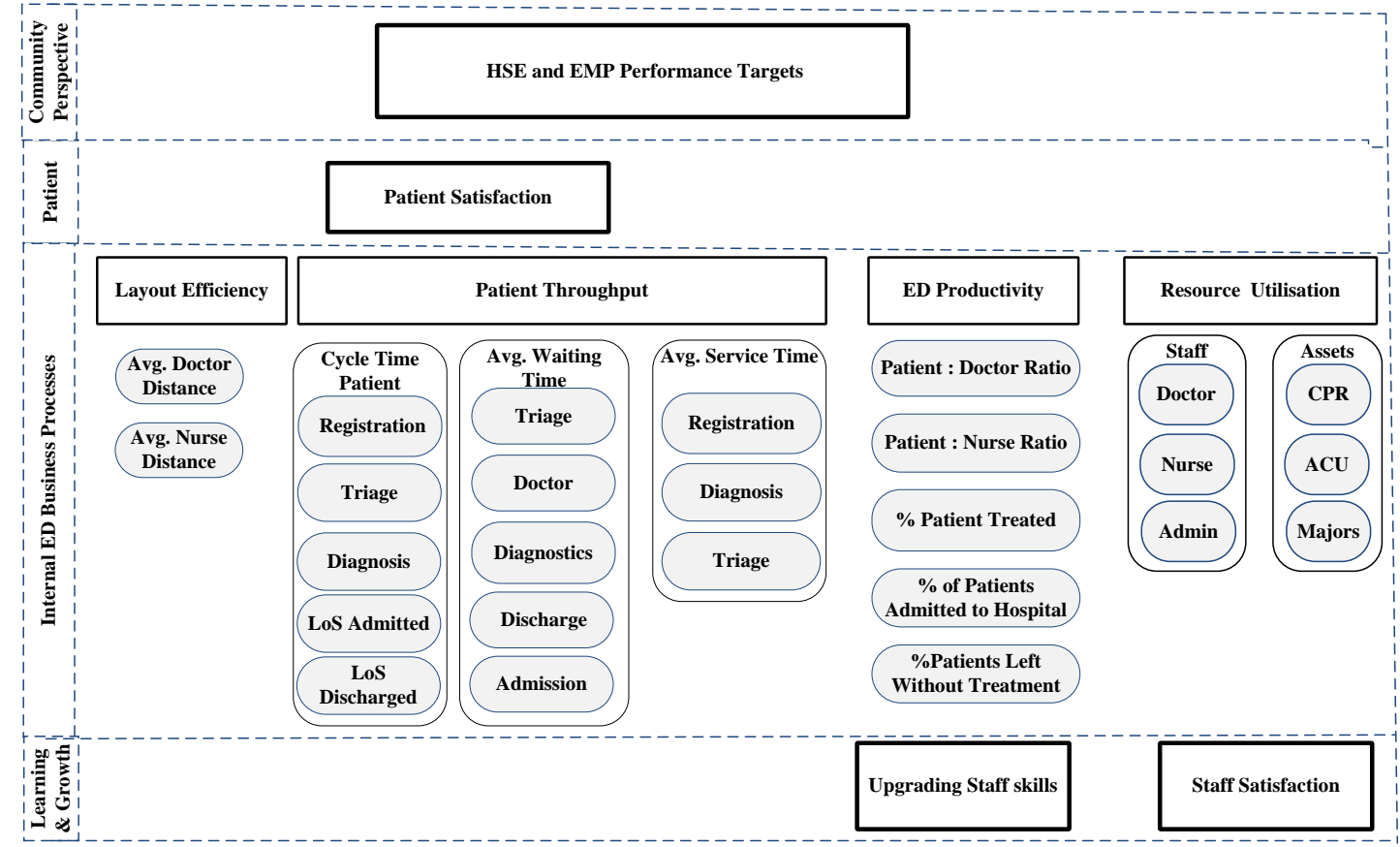

Figure 5 The emergency department balanced scorecard

Patient throughput is measured via three dimensions: average patient cycle times, average patient waiting times, and average patient service (processing) times. The total patient cycle time is measured across the different stages of a patient's journey in the ED such as registration, triage, treatment, and diagnostics. This includes LOS for both admitted and discharged patients. Similarly, patients' average waiting times are detailed for each stage, for example, the average wait for triage, to be seen by ED physician, and for discharge or hospital admission.

Learning and Growth Perspective: Two main performance measures are selected in this perspective: staff development and staff satisfaction levels. The former is measured in terms of the effect of training the staff to do more than one task so that they can be allocated dynamically within the ED. The latter is related to 'internal ED business processes' perspective through the following indicators: staff utilisation, ratio of patients per doctor, and ratio of patients per nurse.

\section{Data Analysis}

A focus group for historical data collection was formed to discuss issues related to electronic patient records, existing information systems, and data entry procedures. The focus group included members from the information system department in the partner hospital. The discussions with the focus group was supported by a close observation of the data entry 
procedures through the patient journey and by a series of short interviews with the ED staff (e.g. registration staff, triage nurses, and physicians). A total of 59,986 anonymous patient records have been collected over a 16-month period which track the patient data during normal operations by using a real-time patient tracking information system. Each patient record details the following patient-level variables: (1) the patient arrival mode, (2) the date/time the patient attended the ED, (3) date/time of patient triage, (4) the triage category assigned to patient; (5) date/time patient seen by doctor, (6) the medical complaint presented by the patient and (7) whether the patient left without being seen, was discharged, or was admitted to the hospital. Patients' records were analysed to extract quantitative information about their arrival patterns, patient groupings and allocations, and routing information. Patients were grouped based on their triage category. Table 1 summarises the analysis of patient information for each triage category along with their arrival mode.

Table 1 Summary of the analysis of patients' records

\begin{tabular}{|c|c|c|c|}
\hline \multirow{2}{*}{$\begin{array}{c}\text { Triage } \\
\text { Category }\end{array}$} & \multirow{2}{*}{$\begin{array}{c}\% \text { of } \\
\text { Patients }\end{array}$} & \multicolumn{2}{|c|}{ Arrival Mode } \\
\hline & & Walk-in & Ambulance \\
\hline IMM & $1.1 \%$ & $5 \%$ & $95 \%$ \\
\hline VURG & $16.5 \%$ & $40 \%$ & $60 \%$ \\
\hline URG & $58 \%$ & $61 \%$ & $39 \%$ \\
\hline STD & $23.9 \%$ & $81 \%$ & $19 \%$ \\
\hline NURG & $0.5 \%$ & $72 \%$ & $28 \%$ \\
\hline
\end{tabular}

An estimated distribution of patient inter-arrivals was used to input arrival patterns for each patient group into the simulation model.

Regarding patient allocation data, Table 2 shows the analysis of the places/locations to which patients were allocated within the ED. The analysis shows that the ED staff were unable to implement the MTS triage recommendations concerning the disposition of patients fully. Thus $88 \%$ of 'Immediate' category patients were seen in the resuscitation room and $9 \%$ in the majors' cubicles, while $40 \%$ percent of very urgent patients were seen in inappropriate assessment areas (e.g. ACUs). Moreover, due to the overcrowded nature of the ED, the majority of standard and non-urgent patient were assessed and treated in inappropriate areas (e.g., chairs or waiting areas).

Table 2 Analysis of patient allocation within the emergency department

\begin{tabular}{lcccccc}
\hline \multirow{2}{*}{ ED Areas } & \multicolumn{5}{c}{ Triage Category } \\
\cline { 2 - 7 } & IMM & VURG & URG & STD & NURG \\
\hline Resuscitation Room & $88 \%$ & $25 \%$ & $2 \%$ & $0 \%$ & $0 \%$
\end{tabular}




\begin{tabular}{|c|c|c|c|c|c|}
\hline Majors Area & $9 \%$ & $15 \%$ & $8 \%$ & $1 \%$ & $0 \%$ \\
\hline Ambulatory Care Unit & $0 \%$ & $12 \%$ & $10 \%$ & $20 \%$ & $11 \%$ \\
\hline Majors Chairs & $0 \%$ & $7 \%$ & $6 \%$ & $1 \%$ & $1 \%$ \\
\hline Rapid Assessment Triage & $3 \%$ & $12 \%$ & $7 \%$ & $2 \%$ & $2 \%$ \\
\hline Waiting Room & $0 \%$ & $14 \%$ & $56 \%$ & $74 \%$ & $85 \%$ \\
\hline X-Ray Sub-Wait Area & $0 \%$ & $15 \%$ & $12 \%$ & $4 \%$ & $1 \%$ \\
\hline
\end{tabular}

\section{Simulation Model Development and Validation}

A comprehensive simulation model was developed by the research team for the ED based on the ED business process model, the designed BSC and the analysis of empirical data. The simulation model comprised a number of modules. These modules were linked together in the same way the blocks were linked in the conceptual flow chart; this facilitated the model construction phase. The top leve of the simulation model defined the overall model structure and the sub-level blocks containing additional modules with greater detail. Object-oriented programming was used to customise pre-defined blocks for constructing the ED simulation model. Moreover, a relational database was used to save the measured KPIs after each simulation run, after which the populated BSC data was exported in tabular form for future analysis and validation. To reduce the time of model development cycle and to increase the confidence of the ED simulation model results, verification and validation were carried out throughout the development phases of the model. Furthermore, each model development phase was verified and validated against the previously completed phases. The verification of the model's logic was carried out to ensure that patients in the simulation model follow the correct expected care paths; this was achieved by visual tracking patients (using animation) and checking intermediate output values such as queue lengths and waiting times between processes. The conceptual model was documented and validated by circulating it among ED senior managers and senior nursing staff, a crucial step to ensure the logics of the model and ED activities were correct. All distributions determined from the data and used in the model were validated using Kolmogorov Smirnov goodness of fit test with a $5 \%$ significance level (Massey, 1951). Simulation variables - such as patients inter-arrival time, mode of arrival, presenting medical complaints, processing time, routing and allocation - were initialised based on the analysis of empirical data and also the analysis of the ED layout and patient flow given in previous sections. Queues at each stage of patient care (e.g. triage, seen by 
doctor, awaiting admission, and discharge) were set as empty and idle. A warm-up period of two months was found to mitigate any bias introduced by the initial conditions of the simulation model. The final results of the simulation model were validated using three techniques; face validation, comparison testing, and hypothesis testing. Face Validation was performed by interviewing ED senior managers and nursing staff to validate the final results of the simulation model. Comparison Testing involved comparing the output of the simulation model with the real output of the system under identical input conditions (Balci, 1997). Three main KPIs are used in this approach; average waiting times until seen by doctor, average LOS for discharged patients, and average LOS for admitted patients. In addition to the overall averages for all patients, detailed data for each KPI was also calculated for 3 triage categories: VURG, URG, and STD. Based on the comparison testing approach, the deviation between actual and simulated results for these KPIs ranged from $1 \%$ to $11 \%$ with an average of only $6 \%$ (Figure 6).

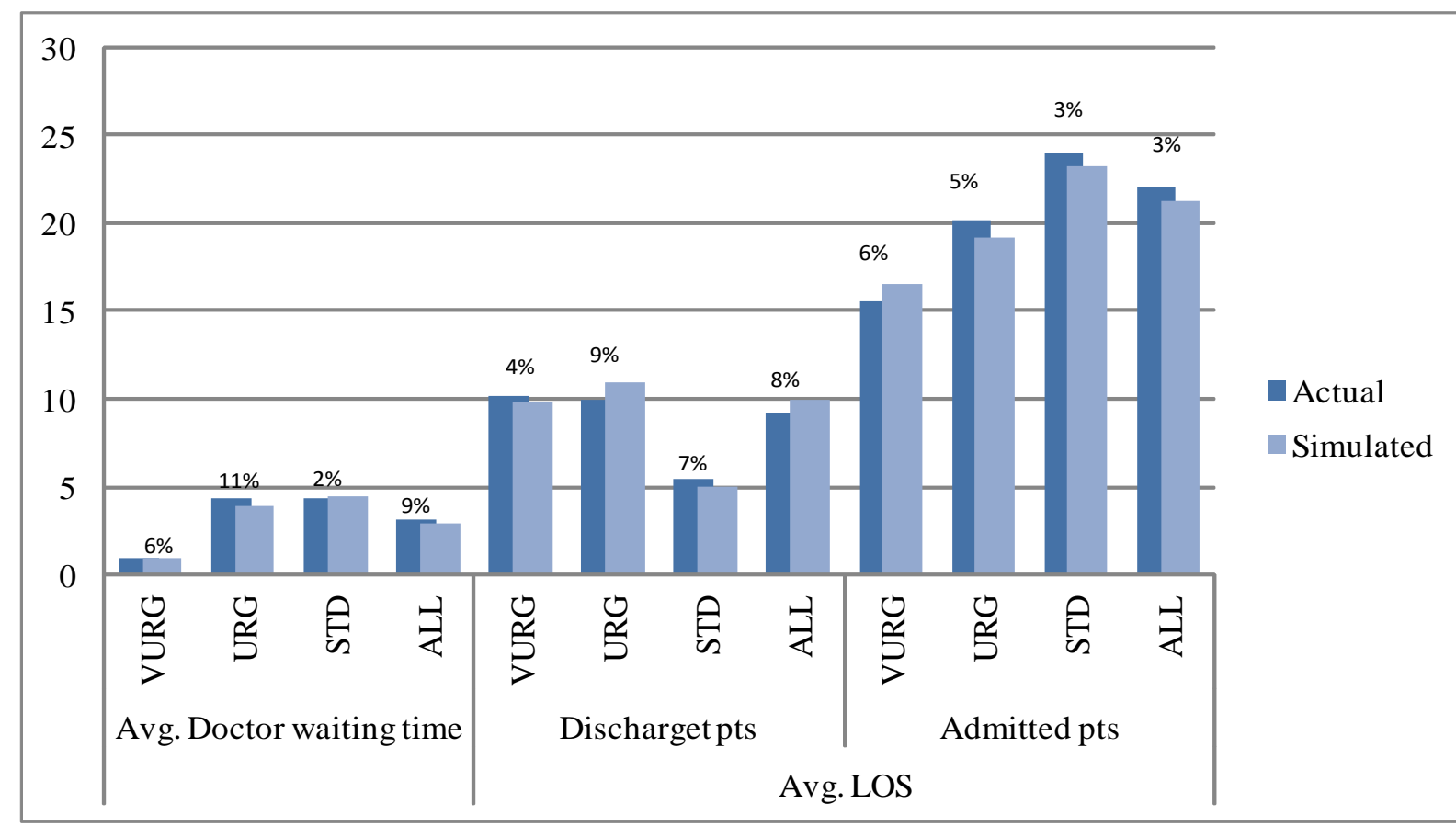

IMM: Immediate VURG: Very Urgent URG: Urgent STD: Standard NURG: Non-Urgent

Figure 6 Validation of simulation results against actual data

The comparison in Figure 6 shows that waiting times for urgent patients (URG) has the largest deviation (11\%), which is reflected in the total average LOS for the same group of patients (9\% for discharged patients and 5\% for admitted patients). According to the ED 
consultants, urgent patients (which represent $60 \%$ of patients attending the ED) are the most challenging and diverse group of patients with a wide range of medical complains and aging conditions. The underlying assumptions used to build the simulation model have also factored in such deviation. For example, only staff activities related to direct contact with patients were considered; other routine work and break-times could not be considered due to the high level of variations in these activities and lack of accurate data.

\section{KEY PERFORMANCE INDICATORS SELECTION}

The BSC developed for the ED in the previous section includes qualitative measures - such as patient satisfaction, staff skills upgrading and staff satisfaction - as well as quantitative measures. Although these measures cannot be measured directly in the simulation, they are directly related to the quantitative performance measures in the 'Internal Business Processes' perspective, which can be directly measured in the simulation model. Nevertheless, there is a level of redundancy between the performance measures in the internal ED business process perspective - for example, '\%age of Patients Treated' and ‘\%age Patients Leaving without Treatment' are clearly complementary, while some ED measures - such as staff utilisation and staff satisfaction - may actually conflict: thus maximising staff utilisation may reach burnout levels (i.e., $85 \%$ utilisation) which then decreases staff satisfaction levels and in turn lead to deteriorating whole-ED performance. Consequently, to narrow down the list of the measures and to achieve a useful trade-off between conflicting objectives, MCDA tools are used to select the main key performance indicators (KPIs) Systematically.

The selection process is based on the simple multi-attribute rating technique (SMART) (Barron and Barrett, 1996) to identify the alternatives and criteria which are relevant to the decision problem. SMART begins with identifying the alternatives (in this case, performance measures in the BSC), and specifying the criteria to be used for evaluating them- the SMART procedure is applied to the performance measures in the 'Internal ED business processes' perspective since these measures are interrelated with other performance perspectives and measures, such as patient and staff satisfaction indicators. Therefore, the 26 performance measures within this perspective are considered as the 'decision alternatives' for the SMART procedure, and are then evaluated against the main ED performance drivers namely layout efficiency, patient throughput, ED productivity, and resource utilisation. Once the alternatives and criteria were identified, a value tree was produced (as shown in Figure 7): the root of the 
tree represents the ED performance, the first level represents the evaluation criteria and the second level represents the candidate alternatives.

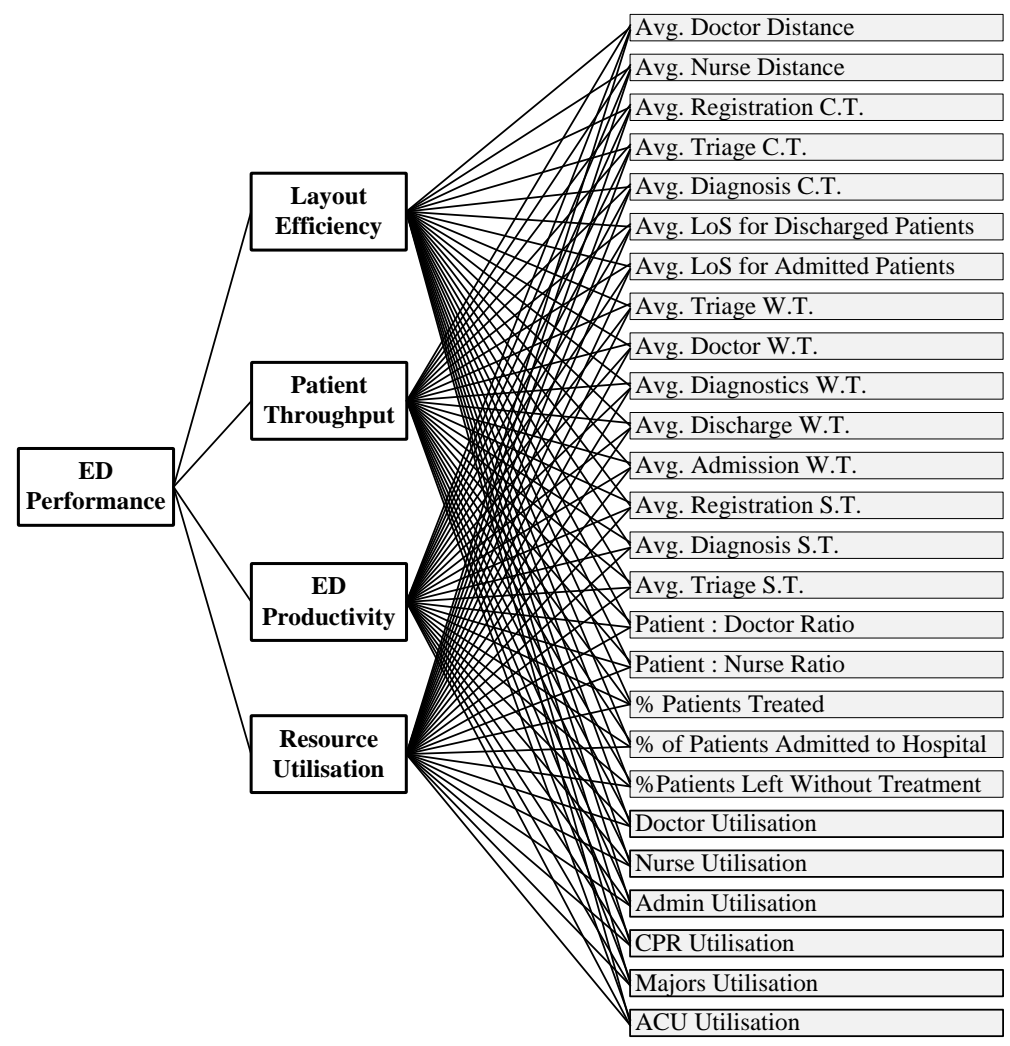

Figure 7 Alternatives' value tree

The ED managers were asked to rank the alternatives with respect to each criterion in order, from the most to least preferred, on an easy-to-use value scale (Valiris et al., 2005). For each criterion, a value of 100 was given for the most relevant measure and 0 to the least relevant. With respect to the 'layout efficiency' criterion, for example, the 'average distance travelled by doctors' within the ED was seen as the most relevant and the 'average patient registration service time' as the least relevant. Table 3 represents preferences for each of the four main criteria.

Table 3 ED senior managers' rating of alternatives for each criterion

\begin{tabular}{r|cccc}
\multicolumn{2}{c}{} & \multicolumn{4}{c}{ Evaluation Criteria } \\
\cline { 2 - 5 } Alternatives & $\begin{array}{c}\text { Layout } \\
\text { Efficiency }\end{array}$ & $\begin{array}{c}\text { Patient } \\
\text { Throughput }\end{array}$ & $\begin{array}{c}\text { ED } \\
\text { Productivity }\end{array}$ & $\begin{array}{c}\text { Resource } \\
\text { Utilisation }\end{array}$ \\
\hline Avg. Doctor Distance & $\mathbf{1 0 0}$ & 50 & 70 & 90 \\
Avg. Nurse Distance & 90 & 50 & 70 & 80 \\
Avg. Registration C.T. & 10 & 60 & 20 & 20 \\
Avg. Diagnosis C.T. & 20 & 60 & 50 & 20 \\
Avg. Triage C.T. & 20 & 30 & 50 & 10 \\
Avg. LoS for Discharged Patients & 30 & $\mathbf{1 0 0}$ & 30 & 70 \\
\hline
\end{tabular}




\begin{tabular}{r|cccc}
\hline Avg. LoS for Admitted Patients & 40 & 90 & 30 & 70 \\
Avg. Triage W.T. & 30 & 20 & 0 & 10 \\
Avg. Doctor W.T. & 60 & 70 & 40 & 40 \\
Avg. Diagnostics W.T. & 10 & 0 & 10 & 10 \\
Avg. Admission W.T. & 20 & 20 & 10 & 20 \\
Avg. Discharge W.T. & 20 & 10 & 10 & 0 \\
Avg. Registration S.T. & 0 & 10 & 10 & 20 \\
Avg. Diagnosis S.T. & 20 & 10 & 20 & 10 \\
Avg. Triage S.T. & 20 & 10 & 10 & 20 \\
Patient to Doctor Ratio & 40 & 80 & 90 & 90 \\
Patient to Nurse Ratio & 40 & 80 & 80 & 90 \\
\% of Patients Treated & 50 & 90 & $\mathbf{1 0 0}$ & 80 \\
\% of Patients Admitted & 30 & 60 & 20 & 70 \\
\% of Patients Left Without Treatment & 20 & 30 & 30 & 30 \\
Doctor Utilisation & 70 & 70 & 90 & $\mathbf{1 0 0}$ \\
Nurse Utilisation & 70 & 70 & 90 & 90 \\
Admin. Utilisation & 10 & 20 & 30 & 20 \\
CPR Trolleys Utilisation & 70 & 70 & 80 & 80 \\
Majors Trolleys Utilisation & 80 & 70 & 80 & 80 \\
ACU Trolleys Utilisation & 60 & 60 & 70 & 70 \\
\hline
\end{tabular}

The other set of remaining alternatives are then rated regarding the most relevant and the least relevant and assigned a value that ranges from 0 to 100 . Because the evaluation criteria were not of equal importance, their relative importance to the overall ED performance was ranked by the ED consultants as shown in Table 4.

Table 4 The relative importance of the evaluation criteria

\begin{tabular}{clcc}
\hline Rank & Criterion & Value score & Normalised weighting \\
\hline 1 & Patient Throughput & 100 & 0.37 \\
2 & ED Productivity & 80 & 0.29 \\
3 & Resource Utilisation & 60 & 0.22 \\
4 & Layout Efficiency & 30 & 0.11 \\
\hline
\end{tabular}

The normalised weighting is calculated by dividing the 'value score' for the particular criterion by the total for all value scores i.e. for rank $1,100 / 270=0.37$. The total score is then calculated for each alternative as the weighted average of the value scores for all of its criteria. For example, Table 5 shows the aggregated weights and value for " $\%$ of Patients Treated'.

Table 5 Aggregated weights and values for ' $\%$ of Patients Treated'

\begin{tabular}{lccc}
\hline Criterion & Value score & Criterion weight & alternative weight \\
\hline Layout Efficiency & 50 & 0.11 & 5.56 \\
Patient Throughput & 90 & 0.37 & 33.33 \\
ED Productivity & 100 & 0.29 & 29.63 \\
Resource Utilisation & 80 & 0.22 & 17.78 \\
Total & & & 86.30 \\
\hline
\end{tabular}


Table 6 summarises the final weighted scores for all the alternatives and specifies the rank of each alternative.

Table 6 Final scores and alternative rankings using SMART procedure

\begin{tabular}{lrr|lrc}
\hline Alternatives & $\begin{array}{c}\text { Total } \\
\text { Score }\end{array}$ & Rank & Alternatives & $\begin{array}{r}\text { Total } \\
\text { Score }\end{array}$ & Rank \\
\hline \% of Patients Treated & 86.30 & 1 & \% of Patients Admitted & 47.04 & 14 \\
\hline Doctor Utilisation & 82.59 & 2 & Avg. Diagnosis C.T. & 43.70 & 15 \\
\hline Patient to Doctor Ratio & 80.74 & 3 & Avg. Registration C.T. & 33.70 & 16 \\
\hline Nurse Utilisation & 80.37 & 4 & Avg. Triage C.T. & 30.37 & 17 \\
\hline Patient to Nurse Ratio & 77.78 & 5 & \% of Patients Left Without & 28.89 & 18 \\
\hline Majors Trolleys Utilisation & 76.30 & 6 & Admin. Utilisation & 21.85 & 19 \\
\hline CPR Trolleys Utilisation & 75.19 & 7 & Avg. Admission W.T. & 17.04 & 20 \\
\hline Avg. Doctor Distance & 70.37 & 8 & Avg. Diagnosis S.T. & 14.07 & 21 \\
Avg. Nurse Distance & 67.04 & 9 & Avg. Triage S.T. & 13.33 & 22 \\
ACU Trolleys Utilisation & 65.19 & 10 & Avg. Triage W.T. & 12.96 & 23 \\
Avg. LoS for Discharged Patients & 64.81 & 11 & Avg. Registration S.T. & 11.11 & 24 \\
Avg. LoS for Admitted Patients & 62.22 & 12 & Avg. Discharge W.T. & 8.89 & 25 \\
Avg. Doctor W.T. & 53.33 & 13 & Avg. Lab W.T. & 6.30 & 26 \\
\hline
\end{tabular}

Finally, the consultants set a cut off level of 50 for the total score for the alternatives to highlight the most important factors and leave the others out of consideration to make the results simpler to use (Figure 8). These final set of alternatives were then passed to the simulation model as the simulation output. 


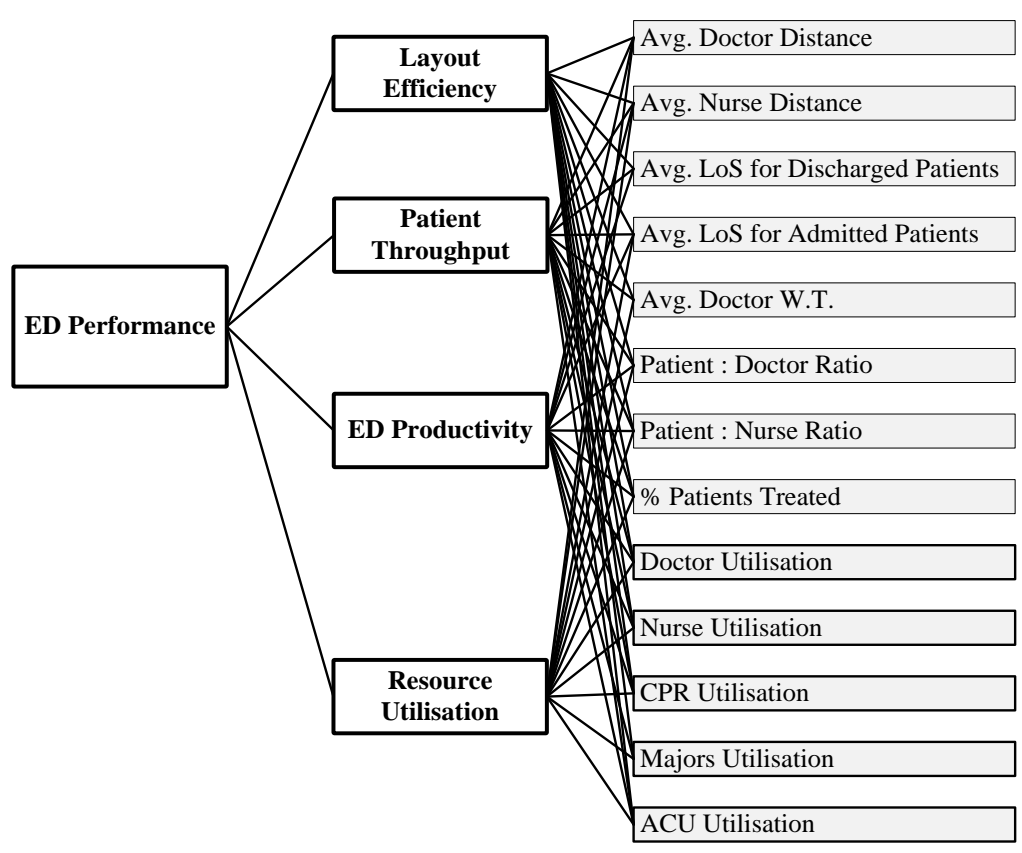

Figure 8 ED Key Performance Indicators

\section{REAL-TIME STRATEGIES FOR THE EMERGENCY DEPARTMENT}

\section{Scenario Design}

The main scenarios introduced involved increased clinical assessment resources (adding 6 extra trolley cubicles), increased availability of clinical assessors (adding 1 extra Senior House Officer shift at night);, and absolute compliance with the national 6-hour admission target (zero-tolerance) (Table 7). Each Scenario runs for continuous 3 month blocks, a period identified by ED managers as being generally associated with stable ED staffing levels

Table 7 Simulation variables for baseline system and scenarios

\begin{tabular}{lrcc}
\hline & \multicolumn{3}{c}{ Decision Variables } \\
\cline { 2 - 4 } Scenarios & Access Block & Physical capacity & Staff \\
\hline Base Line & Yes & 13 & - \\
Capacity Expansion & Yes & 19 & - \\
Increasing Staff & Yes & 13 & 1 SHO [9pm to 7am] \\
Zero-Tolerance & No & 13 & - \\
\hline
\end{tabular}

The scenarios were suggested by the ED senior managers to evaluate the proposed new hospital extension which was intended to include rebuilding of key parts of the facility including the ED. As expanding the ED capacity was likely eventually to necessitate 
corresponding increases in its staffing levels, hospital managers and those planning the new ED were interested in evaluating the effects of capacity and staffing levels expansion against the effects of unblocking critical performance bottlenecks such as the 'access block' from the ED to the hospital.

\section{Analysis of Results}

The results of the simulation model (see Table 8) showed that adopting scenario 3 (absolute enforcement of the national 6-hour admission target) had the most significant impact on the average LOS at every stage of patients through the ED. Average LOS for patients who are ultimately discharged directly from ED reduced from $10.23 \mathrm{hrs}$ to $5.3 \mathrm{hrs}$ (48\% improvement in LOS).

Table 8 Simulation results of scenarios 1,2 and 3

\begin{tabular}{|c|c|c|c|c|c|c|c|c|}
\hline \multirow{2}{*}{\multicolumn{2}{|c|}{ Key Performance Indicators (KPIs) }} & \multirow{3}{*}{$\begin{array}{r}\begin{array}{l}\text { Base } \\
\text { Line }\end{array} \\
2.96\end{array}$} & \multirow{2}{*}{\multicolumn{2}{|c|}{$\begin{array}{l}\text { Capacity } \\
\text { Expansion }\end{array}$}} & \multirow{2}{*}{\multicolumn{2}{|c|}{$\begin{array}{l}\text { Increasing } \\
\text { Staff }\end{array}$}} & \multirow{2}{*}{\multicolumn{2}{|c|}{$\begin{array}{c}\text { Zero } \\
\text { Tolerance }\end{array}$}} \\
\hline & & & & & & & & \\
\hline \multirow{3}{*}{$\begin{array}{l}\text { Patient } \\
\text { Throughput }\end{array}$} & A.W.T Doctor (hrs) & & 2.50 & $15 \%$ & 2.80 & $5 \%$ & 1.80 & $39 \%$ \\
\hline & Avg. LOS Dis. Pts. (hrs) & 10.23 & 8.40 & $18 \%$ & 9.80 & $4 \%$ & 5.30 & $48 \%$ \\
\hline & Avg. LOS Adm. Pts. (hrs) & 21.30 & 18.20 & $15 \%$ & 19.80 & $7 \%$ & 5.70 & $73 \%$ \\
\hline \multirow{5}{*}{$\begin{array}{l}\text { Resource } \\
\text { Utilisation }\end{array}$} & Doctor Utilisation & $81 \%$ & $84 \%$ & $4 \%$ & $73 \%$ & $10 \%$ & $86 \%$ & $7 \%$ \\
\hline & Nurse Utilisation & $82 \%$ & $87 \%$ & $7 \%$ & $83 \%$ & $1 \%$ & $74 \%$ & $10 \%$ \\
\hline & CPR Utilisation & $91 \%$ & $86 \%$ & $6 \%$ & $91 \%$ & $0 \%$ & $87 \%$ & $5 \%$ \\
\hline & Majors Utilisation & $94 \%$ & $82 \%$ & $13 \%$ & $92 \%$ & $2 \%$ & $85 \%$ & $10 \%$ \\
\hline & ACU Utilisation & $93 \%$ & $75 \%$ & $19 \%$ & $94 \%$ & $2 \%$ & $83 \%$ & $11 \%$ \\
\hline \multirow{2}{*}{$\begin{array}{l}\text { Layout } \\
\text { Efficiency }\end{array}$} & $\begin{array}{l}\text { Avg. Doctor Distance } \\
(\mathrm{km} / \mathrm{d})\end{array}$ & 3.24 & 3.63 & $12 \%$ & 2.83 & $13 \%$ & 3.91 & $21 \%$ \\
\hline & Avg. Nurse Distance $(\mathrm{km} / \mathrm{d})$ & 6.48 & 7.32 & $13 \%$ & 6.55 & $1 \%$ & 5.34 & $18 \%$ \\
\hline \multirow{3}{*}{$\begin{array}{l}\text { ED } \\
\text { Productivity }\end{array}$} & Patient : Doctor Ratio & 7.34 & 7.52 & $2 \%$ & 7.14 & $3 \%$ & 7.9 & $8 \%$ \\
\hline & Patient : Nurse Ratio & 9.84 & 10.22 & $4 \%$ & 10.16 & $3 \%$ & 10.8 & $10 \%$ \\
\hline & $\%$ Patients Treated & $83 \%$ & $85 \%$ & $2 \%$ & $90 \%$ & $8 \%$ & $96 \%$ & $16 \%$ \\
\hline
\end{tabular}

The changes that followed from the first two scenarios - namely "capacity expansion" and "increasing staff" - resulted only in less improvements which were neither clinically significant nor improved patient experience (i.e., had a negligible impact on avg. LOS for admitted patients). The "zero-tolerance" scenario improved how the department utilised its physicians, and was also expected to improve the avg. LOS of patients waiting to be admitted to the hospital. 
In order to consider the preferences of the ED managers in the analysis of these scenarios, analytical hierarchical process (AHP) was used. Table 9 presents the AHP comparison matrix for the four main ED performance criteria and their corresponding weightings.

Table 9 AHP comparison matrix for main KPIs in ED performance criteria

\begin{tabular}{cccccc}
\hline & LE & PT & PR & RU & Resulting AHP Weight \\
\hline LE & 1 & 0.125 & 0.167 & 0.25 & 0.046 \\
PT & 8 & 1.000 & 3.000 & 6.00 & 0.581 \\
PR & 6 & 0.330 & 1.000 & 3.00 & 0.285 \\
RU & 4 & 0.167 & 0.330 & 1.00 & 0.116 \\
\hline
\end{tabular}

LE Layout Efficiency PT: Patient Throughput PR ED Productivity $\boldsymbol{R U}$ Resource Utilisation

A comparison matrix for each criterion was then constructed to obtain the weights of individual KPIs. Table 10 shows the comparison matrix for the three KPIs representing the 'Patient Throughput' criterion and their AHP weightings.

Table 10 The comparison matrix for the KPIs of the Patient Throughput criterion

\begin{tabular}{ccccc}
\hline & Avg. LOS Dis. & $\begin{array}{c}\text { Avg. LOS } \\
\text { Ad. }\end{array}$ & AWT Doc. & AHP Weight \\
\hline Avg. LOS Dis. & 1 & 0.33 & 4 & 0.304 \\
Avg. LOS Ad. & 3 & 1 & 3 & 0.575 \\
AWT Doc. & 0.25 & 0.33 & 1 & 0.121 \\
\hline
\end{tabular}

The same process of comparing pairs of KPIs for each main criterion was repeated until the last level was reached. Figure 9 shows the final weights for all the levels in the performance value tree. After calculating the relative weightings, ED managers determined the acceptable range for each KPI by. For example, staff utilisation (for nurses and doctors) was given a range between $50 \%$ and $85 \%$ to avoid burnout levels (of $85 \%$ ). Similarly, a range between 0 and 6 was specified to the LOS KPI specified to measure the levels achieved by each scenario while keeping to the 6-hours maximum HSE target. After the acceptable ranges had been assigned, a value function was attached to each individual KPI to describe the desirability of achieving different performance levels 


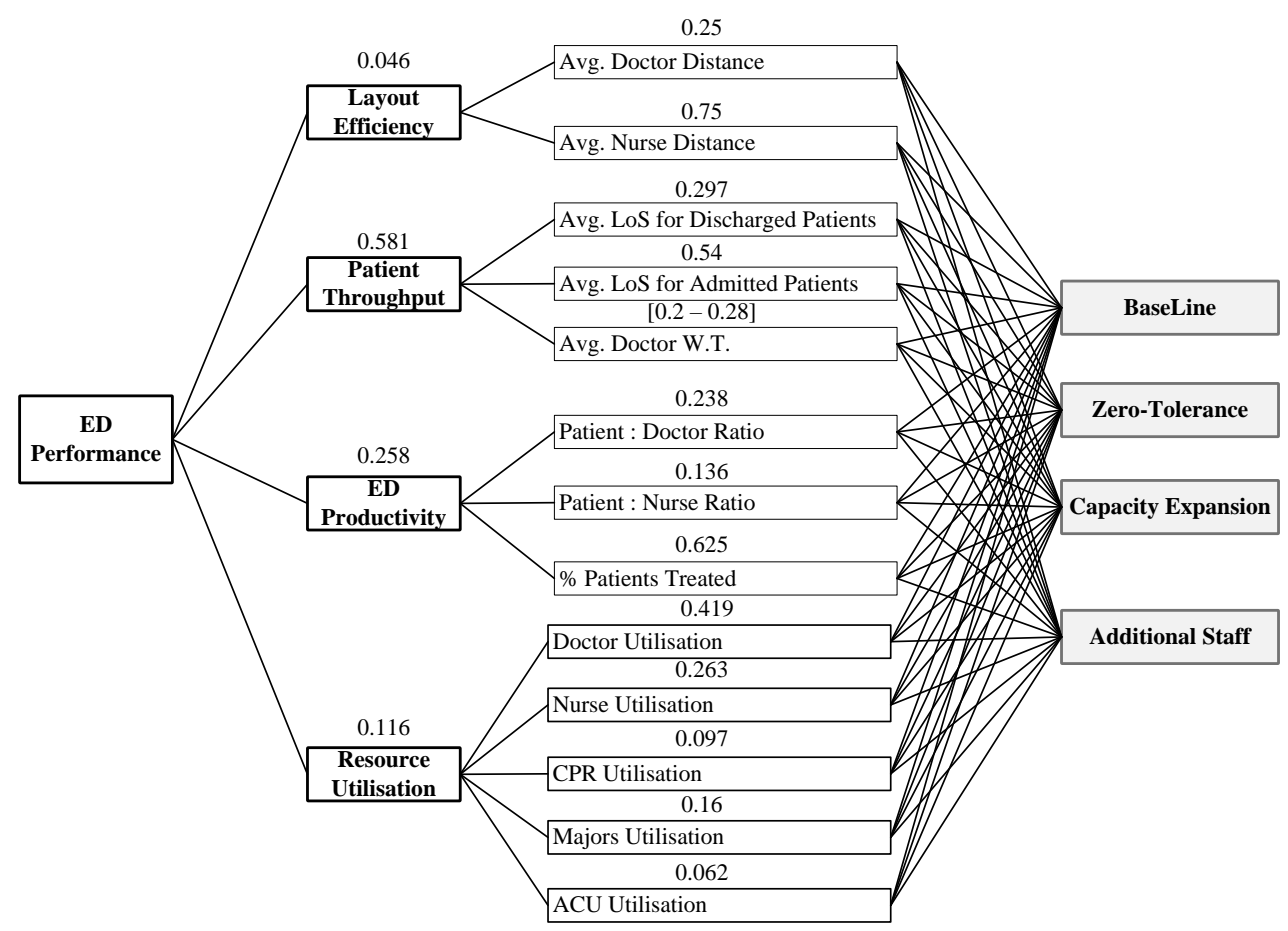

Figure 9 Full AHP weighted value tree

Given the results of the simulation model reported in Table 8, and the AHP preference model in Figure 10, the final value for each scenario including the base line scenario (which was set as the current ED operation) was aggregated and summarised in Table 11.

Table 11 Weighted results for all scenarios against the baseline scenario

\begin{tabular}{llccc}
\hline & Base Line & $\begin{array}{l}\text { Capacity } \\
\text { Expansion }\end{array}$ & $\begin{array}{l}\text { Increasing } \\
\text { Staff }\end{array}$ & Zero-Tolerance \\
\hline Resource Utilisation & 0.11 & 0.14 & 0.108 & 0.19 \\
ED Productivity & 0.169 & 0.18 & 0.194 & 0.215 \\
Patient Throughput & 0.214 & 0.38 & 0.289 & 0.546 \\
Layout Efficiency & 0.031 & 0.034 & 0.031 & 0.029 \\
ED Performance & 0.524 & 0.734 & 0.622 & 0.98 \\
\hline
\end{tabular}

The analysis of the AHP results showed that if the hospital will implement the 'zerotolerance' strategy this will have the most significant impact on the throughput of patients (producing 54.6\% increases), and on the overall ED performance (Figure 10). 


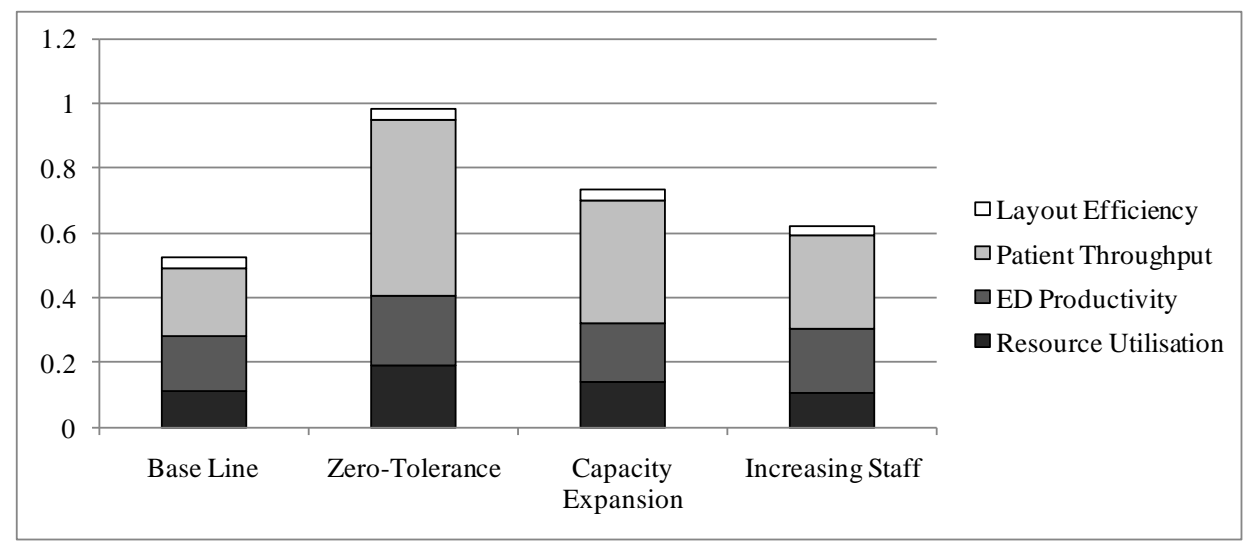

Figure 10 The ED performance for all the scenarios against the current ED.

\section{Sensitivity Analysis}

Recognising the aspects to which the decision is sensitive enables the ED manager to concentrate on, or possibly reconsider the issues, which may cause changes in the decision. Accordingly, a sensitivity analysis was conducted to explore how the ED performance may change according to each strategy and how sensitive each strategy is to variations in performance measures. Figure 11 shows the sensitivity of proposed scenarios to the variation in average LOS. The increase of the ALOS for the current ED above 6-hrs will deteriorate the performance of the current ED at all levels, which necessitates the addition of more staff and the expansion of the ED at this stage. However, enforcing the 6-hrs target (i.e., zero-tolerance scenario) outperformed these more expensive scenarios (i.e., capacity expansion and additional staff) as shown in Figure 12.

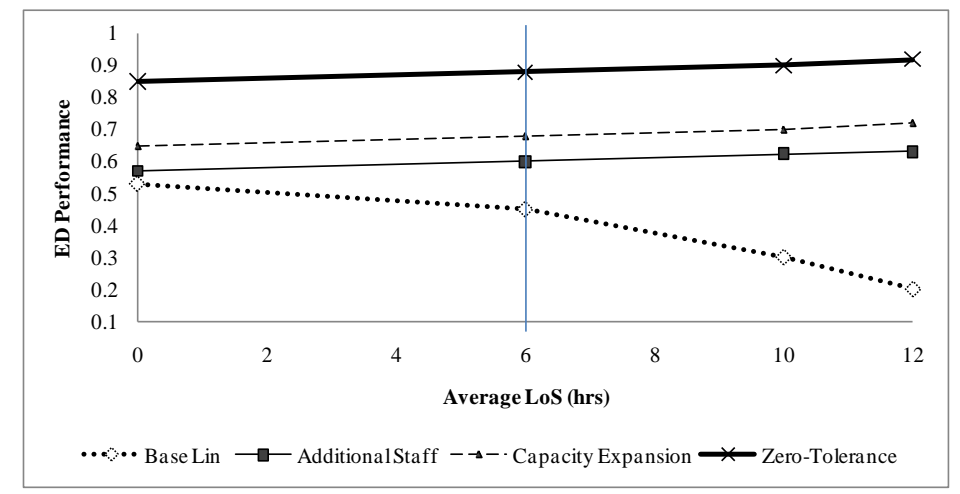

Figure 11 The change in ED performance with average LOS for all scenarios. 
Figure 12 shows how the performance of the ED as currently set up risks deteriorating when staff are over-utilised to the point where they reach their burnout level (i.e., 85\%). As the sensitivity analysis suggests that this risk can be better mitigated by increasing the ED's staffing levels than by expanding its physical capacity, which does not reduce the work load on individual staff members.

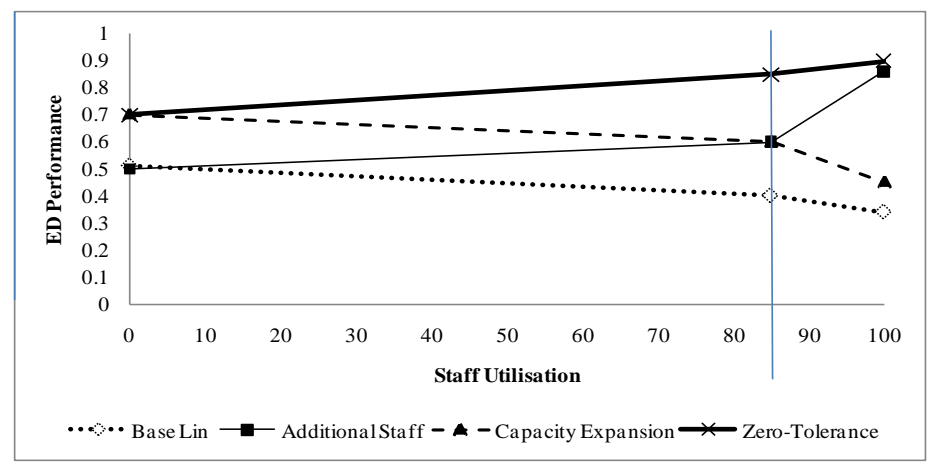

Figure 12 ED performance showing staff utilisation and burnout levels.

This strategy enables ED management to use their resources (e.g. physical beds and trolleys) for helping not only patients awaiting admission but also newly arrived patients. Moreover, nursing staff that were frequently monitoring patients in critical medical conditions in corridors or trolleys can be reallocated to more pressurised areas in the ED.

Therefore the hospital management team has suggested three initiatives in order to implement the recommendations of this study. First, executing an escalation plan that includes placing of additional beds on inpatient wards for moving patients quickly who are waiting in the ED. Secondly, contracting cheaper beds in community care for elderly patients. This will shorten the average LOS in the whole hospital and consequently more beds will be available for ED admissions. Finally, initiating a lean training across all departments in the hospital with the aim of increasing the coordination level between hospital units and achieving a balanced utilisation of hospital resources.

\section{CONCLUSION}

The proposed framework presented in this paper brought together scientists and clinicians to resolve many challenges that face healthcare managers in the ED setting. Developing a detailed and comprehensive model that duplicated a real process allowed managers to use a 'what if' analysis approach to examine strategies and enhance their decision making. 
The proposed framework has been well-received by the ED managers and the hospital senior decision makers and was acknowledged as a sustainable tool to support their strategies. A number of factors have contributed to this positive perception from the management team. Firstly, the development of a high-level process model prior to the development of the simulation model has greatly helped in the collection of relevant information on the operation of the system (i.e. data collection) and, therefore, reduced the effort and time consumed to develop the simulation model. The utilisation of IDEF for process modelling has not only improved the quality of the simulation model but it also enhanced the level of communication between decision makers and the staff through modelling the underlined work flow, decision points, and processes in a hierarchical form. Secondly, the integration between simulation modelling and balanced scorecard established a clear link between the strategic objectives of the hospital and the daily activities within the department, which gave decision makers deep insights regarding performance bottlenecks and potential corrective plans. Finally, the combination of multi-criteria decision analysis tools along with simulation and BSC contributed significantly in the decision making process by explicitly dealing with priorities and trade-offs between different performance measures.

The recommendations of the framework have been considered by the executive board of the partner hospital where the framework is currently used to model other hospital processes that affect the flow of patients to achieve the required alignment and coordination between hospital units.

Although the proposed framework has successfully encompassed many factors that affect decision making, there is still a room for improvement. The key limitation of the proposed framework is the cost factor of the decision. Incorporating the cost element was not possible in this study due to two main reasons; (1) lack of cost related information to support the analysis phase and, (2) the variability in the cost model in various public hospitals in Ireland created a high level of complexity to model the financial element. The proposed framework is also limited to Discrete-Event Simulation (DES), other simulation and modelling methods such as system dynamics (SD) and agent-based simulation (ABS) are emerging as potential tools for analysing the inter-connected relationships between healthcare components at the macro-level of the system. 


\section{REFERENCES}

AHMED M A AND ALKHAMIS T M (2009) Simulation optimization for an emergency department healthcare unit in Kuwait. European Journal of Operational Research, 198: 936-942.

BALCI O (1997) Verification validation and accreditation of simulation models. In: ANDRADÓTTIR S, HEALY K J, WITHERS D H AND NELSON B L (Eds). Proceedings of the 1997 Winter simulation Conference, Atlanta, Georgia, USA. 135-141.

BARRON F H AND BARRETT B E (1996) The efficacy of SMARTER - Simple Multi-Attribute Rating Technique Extended to Ranking. Acta Psychologica, 93: 23-36.

BRAILSFORD S AND VISSERS J (2011) OR in healthcare: a European perspective. European Journal of Operational Research, 212: 223-234.

CONNELLY L G AND BAIR A E (2004) Discrete event simulation of emergency department activity: a platform for system level operations research. Academic Emergency Medicine, 11: 11771185 .

CRONIN J (2003) The introduction of the Manchester triage scale to an emergency department in the Republic of Ireland. Accident and Emergency Nursing, 11: 121-125.

DITTUS R S, KLEIN R W, DEBROTA D J, DAME M A AND FITZGERALD J F (1996) Medical resident work schedules: design and evaluation by simulation modeling. Management Science, 891906.

ELDABI T, PAUL R AND YOUNG T (2006) Simulation modelling in healthcare: reviewing legacies and investigating futures. Journal of the Operational Research Society, 58: 262-270.

GWET K L (2008) Computing inter rater reliability and its variance in the presence of high agreement. British Journal of Mathematical and Statistical Psychology, 61: 29-48.

INGOLFSSON A, ERKUT E AND BUDGE S (2003) Simulation of single start station for Edmonton EMS. Journal of the Operational Research Society, 54: 736-746.

KAPLAN R S AND NORTON D P (1992) The balanced scorecard-measures that drive performance. Harvard Business Review, 70: 71-79.

KAPLAN R S AND NORTON D P (2001) The Strategy-Focused Organization: How Balanced Scorecard Companies Thrive in The New Business Environment. Harvard Business Press: Boston, MA.

KIM S C, HOROWITZ I, YOUNG K K AND BUCKLEY T A (1999) Analysis of capacity management of the intensive care unit in a hospital. European Journal of Operational Research, 115: $36-46$.

KIM S H AND JANG K J (2002) Designing performance analysis and IDEF0 for enterprise modelling in BPR. International Journal of Production Economics, 76: 121-133.

LEBCIR M R (2006) Health care management: the contribution of systems thinking. University of Hertfordshire, Business School Working Papers UHBS 2006-7.

Litvak N, VAN RIJSBERGEN M, BOUCHERIE R J AND VAN HOUDENHOVEN M (2008) Managing the overflow of intensive care patients. European Journal of Operational Research, 185: 998-1010. 
MASSEY F J (1951) The Kolmogorov-Smirnov test for goodness of fit. Journal of the American Statistical Association, 46: 68-78.

SAATY T L (1990) How to make a decision: the analytic hierarchy process. European Journal of Operational Research, 48: 9-26.

SAMAHA S, ARMEL W S AND STARKS D W (2003) The use of simulation to reduce the length of stay in an emergency department. In: CHICK S, SÁNCHEZ P J, FERRIN D AND MORRICE D J (Eds). Proceedings of the 2003 Winter Simulation Conference, New Orleans, Louisiana, USA, 19071911.

SAUNDERS C E, MAKENS P K AND LEBLANC L J (1989) Modeling emergency department operations using advanced computer simulation systems. Annals of Emergency Medicine, 18: 134140.

SINREICH D AND JABALI O (2007) Staggered work shifts: a way to downsize and restructure an emergency department workforce yet maintain current operational performance. Health Care Management Science, 10: 293-308.

THORWARTH M, ARISHA A AND HARPER P (2009) Simulation model to investigate flexible workload management for healthcare and servicescape environment. In: ROSSETTI M D, HILL R R, JOHANSSON B, DUNKIN A AND INGALLS R G (Eds). Proceedings of the 2009 Winter Simulation Conference, Austin, Texas, USA. 1946-1956.

VALIRIS G, CHYTAS P AND GLYKAS M (2005) Making decisions using the balanced scorecard and the simple multi-attribute rating technique. Performance Measurement and Metrics, 6: 159-171.

ZELMAN W N, PINK G H AND MATTHIAS C B (2003) Use of the balanced scorecard in health care. Journal of Health Care Finance, 29: 1-16. 